\title{
A Social Commerce Intention Model for Traditional E- Commerce Sites
}

\section{Sebastián Molinillo1, Francisco Liébana-Cabanillas ${ }^{2}$ and Rafael Anaya-Sánchez ${ }^{3}$}

${ }^{1}$ University of Málaga, Department of Business Management, Málaga, Spain, smolinillo@uma.es

2 University of Granada, Department of Marketing and Market Research, Granada, Spain, franlieb@ugr.es

3 University of Málaga, Department of Business Management, Málaga, Spain, rafael.anaya@uma.es

Received 20 June 2017; received in revised form 20 September 2017; accepted 13 November 2017

\begin{abstract}
The existing literature mainly analyses user intention to practice social commerce on social networking sites, but few studies have focused on traditional e-commerce sites with their own integrated social tools (e.g. forums, reviews). This research aims to identify the antecedents to social commerce intention for traditional ecommerce sites where social tools are integrated. Data were obtained from a survey of 201 consumers and were analysed using Partial Least Squares. The results indicate that web quality, flow and emotional social support have a positive and direct influence on social commerce intention, while social presence and informational social support are not significant. This study contributes to consumer behaviour theory by applying predictors of intention to social commerce for traditional e-commerce sites. The results also help e-commerce practitioners to improve their use of social tools. For instance, to increase the use of social commerce, web quality must be improved to promote dissemination and consultation of the information generated by users in an easy, quick and friendly way. Social commerce intention will also increase if the company designs efficient interactive processes which the user enjoys effortlessly, so that the website creates a flow experience.
\end{abstract}

Keywords: Retail, Consumer behaviour, E-commerce, Social commerce intention, Partial Least Squares 


\section{Introduction}

Social media has changed how relationships are established in society [52], [59]. Social media are a group of Internet-based applications which facilitate the creation and exchange of user-generated content [32]. Users share information and opinions about products and brands, amongst other functionalities [36]. As such, consumers no longer depend on the information provided by companies through traditional channels or on their websites [7], [48].

Making a purchase is a largely social act [39], meaning that social media relationships have a significant effect on consumer behaviour [25], [36]. With this in mind, e-commerce businesses have incorporated social tools (e.g. forums, chat rooms, recommendation systems, communities, social networks) to help users to contact other consumers and facilitate the purchase decision [39]. This interaction between consumers during the buying process has given rise to the term social commerce (SC) [36]. Although there is no standard definition of the term, "social commerce generally refers to the delivery of e-commerce activities and transactions via the social media environment, mostly in social networks and by using Web 2.0 software" [35] p. 6. Therefore, SC is a form of e-commerce in which customers use social tools to generate, search for and share information and opinions about products, in addition to making a purchase [44], [54], [57], [59]. Traditional e-commerce and SC are different in that the first only incorporates tools to facilitate commercial transactions, whereas the second also has social tools which take commercial advantage of the interactions between the users themselves and between users and the organization [7], [13].

There are two main SC site configurations: social networking sites with integrated commercial features that allow for advertising and transactions (e.g. Facebook); and traditional e-commerce sites with integrated social tools (e.g. Amazon) [35]. Each configuration is designed to meet different objectives and establishes different types of relationships between their users. Whilst traditional e-commerce sites mainly seek usability, web quality, system quality, information quality and playfulness, social networking sites are designed to generate conversations and communities which lead to greater user participation, without jeopardizing system quality [31]. These two types of platform provide different tools: social networking sites centre more on the use of 'like' and 'share' buttons; traditional e-commerce sites make greater use of rating and review systems.

User participation is crucial to SC - without this, the content which is valuable to other consumers would not be generated [35], [36], [44], [57]. It is therefore useful to understand the user motivations which affect their SC intention [27], [59], [60]. Customer participation in SC includes direct and indirect business transactions. 1) Direct transactions encompass purchase behaviour during the purchase phase of a client decision. 2) Indirect transactions include requesting and sharing information (e.g. referral and eWOM) when setting goals, searching for information, product selection and post-purchase, using social tools [59]. User participation enables supply to be better tailored to demand owing to greater information exchange, which increases customer satisfaction and boosts profitability [13], [41].

All of this has led to an increased interest in SC research, although empirical research is still limited [7], [37], [62]. Previous studies have analysed the evolution of SC and how it differs from traditional e-commerce [13], [57], the influence of product recommendation and review systems on consumer behaviour [20], [58], and SC intention for social networks [7], [36], [44], [59], [60]. For the latter, previous studies have analysed such aspects as motivating factors which induce participation (e.g. relationship quality, system quality), links with other users which lead to a greater level of participation, cultural aspects which play a role and user behaviour. That said, although previous research has highlighted differences between SC platforms on social networking sites and traditional e-commerce sites [31], there are few studies on SC intention for the latter. This has led us to the following research questions:

What variables affect social commerce intention on traditional e-commerce sites with integrated social tools? What influence do social tools have on these types of websites?

This study aims to introduce a Social Commerce Intention Model (SCIM) for traditional e-commerce sites which have integrated social tools (e.g. forums, chats, review and rating system). Our research model is based on models by [36], [59], who identified antecedents to SC intention in social networks. The research framework is determined by social support theory, the Stimulus-Organism-Response model and social exchange theory.

Hereafter, the article is structured as follows: first, we set out the conceptual framework and hypotheses development which shape the research model; then, we explain the methodology used and the results of data analysis; lastly, we set out the conclusions and possible future lines of research. 


\section{Literature Review and Hypotheses Development}

The research framework draws on consumer behaviour theories used in previous studies on SC intention for social networking sites. The Stimulus-Organism-Response paradigm was used to study the effect of the technological aspects of SC (e.g. interaction, personalisation and sociability) on the customer's virtual experience (social support, social presence and flow) [59]. This theory highlights that different environmental factors act as stimuli and jointly affect a person's internal state, leading them to behave in different ways [43]. Likewise, social support theory has been used to explain how social variables affect intention to use a website and to share and receive commercial information [36]. The theory indicates that people place much value on feeling looked after and supported by other people, on receiving emotional and informational support, and on feeling part of a community [55]. Social exchange theory maintains that after assessing the benefits obtained from a relationship (e.g. social support), a person may or may not decide to act in a reciprocal manner [6]. This also applies to participation on SC sites [61]. As well as the variables arising from these theories, researchers have emphasised the influence of web quality on SC user behaviour [36]. Our research evaluates the effect of social presence, social support (emotional and informational), flow and web quality on SC intention for a traditional e-commerce site with integrated social tools.

\subsection{Social Commerce Intention}

Since it is difficult to measure an individual's actual behaviour, behavioural intentions are usually used instead [59] and are considered a valid predictor of user behaviour [56]. Behavioural intentions are used in several theories, such as the Theory of Reasoned Action (TRA) and the Theory of Planned Behaviour (TPB), and in the Technology Acceptance Model (TAM) and the Stimulus-Organism-Response model (SOR) [1], [2], [36], [59]. Consumer intentions therefore strongly influence their behaviour. In this research, SC intention is defined as user willingness to generate, search for and share information about products, which enables customers to make better purchase decisions [25], [36], [59]. SC intention therefore refers to the intention of the user to share their experiences and recommend products, and to their purchase intention, taking into account the experiences and suggestions of other users.

Purchase intention has been studied previously for various online environments. For instance, [3] studied purchase intention for virtual environments based on the effects of the technology and the online space in question; [7] analysed the effects of different variables such as community engagement and social support on purchase intention for SC sites; [9] studied the effect of social presence on intention to use online recommendation systems. Attitude and flow were identified as the most significant antecedents to online purchase interaction on e-commerce sites [26]. Also, [38] explained purchase intention in SC environments based on the user's experience of flow. In addition, [44] analysed the cultural differences that may affect purchase intention on SC sites. Lastly, [25] looked at the effects of various SC activities on purchase intention on the respective websites (comments, forums, etc.).

\subsection{Social Support}

Social support is the information that leads a person to believe that they are cared for, loved and respected as a member of a network of people which is built on mutual obligation [36]. Social support is normally considered a multidimensional construct which has two dimensions in the online environment: emotional support and informational support [7]. Informational support is the action of providing recommendations, advice, guidance or useful information that helps solve problems and generate new ideas, etc. [7], [36]. Emotional support is the provision of emotionallycentred messages (looking after other users, empathy, understanding, etc.) which make the recipient feel valued [36]

According to social exchange theory [6], when social support exists in a product-based online community, the members of said community tend to share information and offer recommendations to other users, and to accept the information provided by others [7], [59]. Thus, when a user feels looked after by the community and that the information they receive is useful in their purchase decisions, they will feel obliged to act in a reciprocal manner [11], and may even form friendships and trusting relationships which influence their purchase intentions [36]. There is therefore a positive link between social support and SC intention which, given the two-dimensional nature (i.e. informational and emotional) of the former [7], leads us to make the following hypotheses:

H1: Informational social support has a positive influence on social commerce intention.

H2: Emotional social support has a positive influence on social commerce intention.

\subsection{Flow}

Immersion or flow is a holistic sensation that a person experiences when they are completely absorbed in what they are doing [13]. Users of online environments experience a strong sense of flow when they are fully immersed in the website, which leads to a positive user experience [45]. A website which encourages a flow state creates an 
experience of absorption where the user is more fully engaged in online activities [59] because they feel a greater sense of satisfaction and loyalty [30].

Previous studies have identified the positive influence of flow on purchases and customer recommendations made online [22]. It is a significant antecedent to purchase intention in traditional e-commerce [26], [34] and in SC based on social networks [38], [59]. We can therefore assume that when a user of an e-commerce site with social tools experiences flow, their SC intention increases. This leads us to the following hypothesis:

\section{H3: Flow has a positive influence on social commerce intention.}

\subsection{Social Presence}

Social presence is the degree of salience between two people during communication [51]. That is, the extent to which a person is aware of the other when an interaction takes place and the psychological sense of closeness [3]. SC consumers who experience social presence through interactions with other consumers may feel more comfortable and more emotionally fulfilled [59], and more engaged in the activity [3].

Social presence in e-commerce acts as a mediator between attitudes towards online shopping and behavioural intentions [18], [49]. This effect arises from the links established between consumers, which strengthen their virtual identity and support their participation [3], [21]. The greater sense of social presence causes an increase in consumer participation in SC [9], and has a positive effect on SC intention [59]. We can therefore make the following hypothesis:

H4: Social presence has a positive influence on social commerce intention.

\subsection{Website Quality}

The design and content of e-commerce sites affects their success [36]. Web quality depends as much on the system as on the service provided, usability, enjoyment and the relationships which are established [31], [40]. In SC, web quality has traditionally encompassed both the system and the service provided, since information quality depends on the participation of other users [36]. Service quality encompasses the online support capabilities provided by the website owner, such as purchase order tracking, the speed of response to questions or complaints management. System quality, on the other hand, refers to user control, the scope of the platform and the interface components [31] A quality SC website enables consumers to solve their problems, have a satisfactory experience and feel that the website is a valid environment for establishing social relationships, thus increasing their purchase intention [10], [36]. We can therefore make the following hypothesis:

\section{H5: Web quality has a positive influence on social commerce intention.}

The Social Commerce Intention Model (SCIM) for traditional e-commerce sites in figure 1 shows the relationships established by the hypotheses to be confirmed.

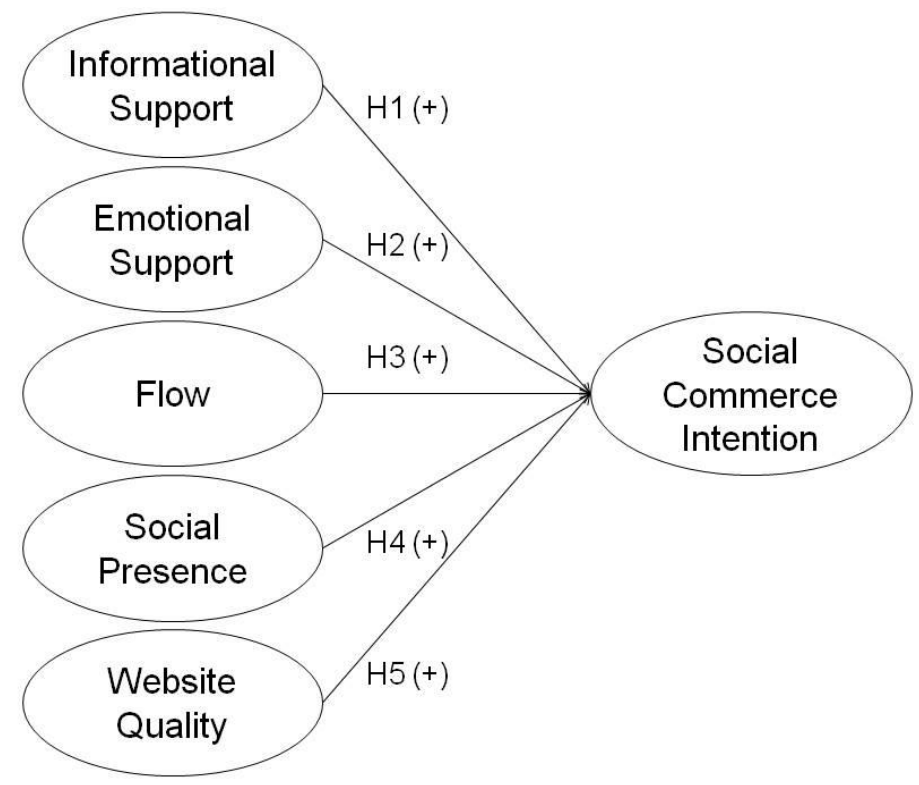

Figure 1: The Social Commerce Intention Model (SCIM) 


\section{Methodology}

Data were gathered between April and May 2016 via an online questionnaire to SC customers. The questionnaire was linked to an e-commerce site selling t-shirts (Site 1). The site has social tools such as forums, product reviews, ratings and comments. The Qualtrics web survey tool was used to build and distribute the questionnaire. Users could answer the questionnaire via a link embedded at the start of the buying process. Participation was voluntary, and there was no reward system to encourage certain profiles. A weekly message encouraged users to take part in the questionnaire, explaining its purpose within the academic research being conducted. Screening questions were included at the start of the process to discourage users who had not previously bought anything on the website. Responses suspected of being dishonest, such as those with repetition and very quick response times, in addition to those from identical IP addresses, were discounted. All incomplete questionnaires were also deleted.

The constructs used in the survey were adapted from previous studies to fit the context of social commerce. Informational Support was adapted from [36]. Emotional Support was adapted from the work of [36]. The Social Presence scale was adapted from research conducted by [59]. Flow was adapted from the scales of [59]. Web Quality was adapted from [36]. Finally, the Social Commerce Intention construct was adapted from [36] (Appendix A).

Five-point Likert scales ranging from "strongly disagree" to "strongly agree" were used to measure all items in the survey. A review was carried out by a panel of ten experts, both for the selected methodology and for the scales selected from the scientific literature, to ensure content validity and suitable wording of all the questions. This process was carried out using personal interviews, by modifying some of the proposed scales and by adapting others to our objective. Afterwards, the questionnaire was divided into three different sections: 1) assessment questions with the aim of confirming the subject's interest and coherence; 2) questions related to the research behavioural model; and 3) questions to gather socio-demographic data for use as control variables to ensure that empirical results were not due to covariance between variables. The initial questionnaire was piloted with a sample of 75 undergraduate and postgraduate students from two public universities in January 2016. The design focussed on assessing and refining the survey to check the acceptance level, dimensionality, reliability and validity of the proposed scales. After all the relevant tests were performed and the relationships and scales set out were verified, we evaluated the proposed model.

We received 201 valid questionnaires. The sample group is mainly Spaniards (94\%), men (64.5\%), younger than 25 $(62.2 \%)$ and with a university education (67\%) (Table 1).

Data analysis was performed using the partial least squares (PLS) approach to structural equation modelling (SEM) with SmartPLS 3 [50]. Structural equation modelling is traditionally based on covariances. However, PLS-SEM is based on variances. PLS-SEM is appropriate when the normality of the data cannot be guaranteed, and allows the researcher to work with small samples [23]. PLS is also appropriate when there is scarce research available, when the research questions have not been looked at in prior studies, or when the analysis is exploratory [47]. We opted for PLS given our research is in an emerging field without normally distributed data and uses a relatively small sample. Note that the sample size clearly exceeds the minimum value of ten times the largest number of inner model paths directed at a particular construct in the inner model [4].

PLS generalises and combines aspects of principal component analysis and multiple regression analysis. PLS structural models are measured using reflective and formative indicators [5]. Given the nature of the epistemological relationships in our research, we opted for reflective constructs where the construct causes the measurement indicators [14]. The research methodology also draws on the bootstrapping technique to check the significance of the coefficients previously assessed using PLS. This technique provides subsamples with randomly extracted observations (with replacements) [24]. We first analysed the effect of multicollinearity between variables. Some authors suggest using the Variance Inflation Factor (VIF) to verify the absence of multicollinearity [15]. This statistic measures the extent of multicollinearity between independent variables in a regression model. Some authors recommend that this value be less than 3.3 [47] or 5 [23], which would indicate an absence of multicollinearity. The VIF results obtained for all the indicators in our model were less than 2.3 and we can therefore assume that multicollinearity is not a problem. After verifying that there was no multicollinearity between indicators, we then assessed the measurement model. 
Table 1: Demographic characteristics of respondents

\begin{tabular}{|l|l|l|}
\hline Demographics & Frequency & Percentage \\
\hline Gender & & \\
\hline Man & 129 & 64.5 \\
\hline Woman & 72 & 35.4 \\
\hline Age range & & \\
\hline Under 18 & & \\
\hline From 18 to 25 & 125 & 62.2 \\
\hline From 26 to 35 & 63 & 31.3 \\
\hline From 36 to 45 & 6 & 3.0 \\
\hline Over 45 & 7 & 3.5 \\
\hline Educational level & & \\
\hline Primary and secondary studies & 50 & 24.8 \\
\hline University studies & 136 & 67.7 \\
\hline Postgraduate Degree & 13 & 6.5 \\
\hline Others & 2 & 1.0 \\
\hline Activity & & \\
\hline Unemployed & 5 & 2.4 \\
\hline Student & 98 & 48.8 \\
\hline Employed by others & 44 & 21.9 \\
\hline Self-employed & 52 & 25.9 \\
\hline Others & 2 & 1 \\
\hline & & \\
\hline
\end{tabular}

\section{Results}

This section explains the results of the data analysis to identify the antecedents of social commerce intention. Firstly, it is described the assessment of the measurement model. Secondly, it is showed the assessment of the structural model.

\subsection{Assessment of the Measurement Model}

The reliability of each item was assessed by examining simple correlations of indicators with their respective variable. A value greater than 0.7 suggests that the variance between the construct and its indicators is greater than the error variance [4]. In our case, all indicators exceed the values recommended in the literature, except a flow indicator (F1), and two social commerce intention indicators ( $\mathrm{SCl} 1$ and $\mathrm{SCl} 2$ ). These were consequently eliminated from the analysis.

To measure the reliability of the scales we used Cronbach's alpha [12] and composite reliability (CR) [46]. All the resulting values are greater than the recommended minimums.

We then assessed convergent and discriminant validity. Convergent validity was assessed using average variance extracted (AVE) [17]. AVE estimates the amount of variance that a construct captures from its indicators in relation to the amount of variance due to the measurement error. In our case, the AVE value is greater than the suggested minimum of 0.5 . Table 2 shows the values of the indicators in the assessment of the measurement model. 
Table 2: Assessment of the measurement model

\begin{tabular}{|l|l|l|l|}
\hline Construct & Cronbach's alpha & CR & AVE \\
\hline Informational Support & 0.862 & 0.915 & 0.782 \\
\hline Emotional Support & 0.909 & 0.936 & 0.785 \\
\hline Flow & 0.835 & 0.890 & 0.669 \\
\hline Social Presence & 0.854 & 0.889 & 0.617 \\
\hline Web Quality & 0.931 & 0.946 & 0.744 \\
\hline Social Commerce Intention & 0.751 & 0.841 & 0.570 \\
\hline
\end{tabular}

Lastly, three PLS methods were used to assess discriminant validity i.e. checking that a construct measures a concept which is different from other constructs: (a) cross-loadings analysis, which looks at whether the average variance between a dimension and its items is greater than the variance between other dimensions in the model [4]; (b) the Fornell-Larcker criterion, which analyses whether the correlations between dimensions are lower than the square root of the AVE [17]; and c) the HTMT ratio (heterotrait-monotrait), which measures correlations between pairs of constructs and should be around 0.9 [29]. The resulting values are close to the limits recommended in the scientific literature. We therefore consider the discriminant validity in the model to be satisfactory. Tables 3 and 4 show the discriminant validity values for each of the above criteria.

Table 3: Discriminant validity and cross-loadings

\begin{tabular}{|l|l|l|l|l|l|l|}
\hline Item & $\begin{array}{l}\text { Informational } \\
\text { Support } \\
\text { (IS) }\end{array}$ & $\begin{array}{l}\text { Emotional } \\
\text { Support } \\
(\text { ES) }\end{array}$ & $\begin{array}{l}\text { Flow } \\
(\mathrm{F})\end{array}$ & $\begin{array}{l}\text { Social Presence } \\
(\mathrm{SP})\end{array}$ & $\begin{array}{l}\text { Web } \\
\text { Quality } \\
(\mathrm{WQ})\end{array}$ & $\begin{array}{l}\text { Social Commerce } \\
\text { Intention (SCI) }\end{array}$ \\
\hline IS1 & $\mathbf{0 . 8 7 6}$ & 0.440 & 0.253 & 0.483 & 0.112 & 0.197 \\
\hline IS2 & $\mathbf{0 . 9 1 1}$ & 0.561 & 0.157 & 0.537 & -0.012 & 0.207 \\
\hline IS3 & $\mathbf{0 . 8 6 5}$ & 0.628 & 0.168 & 0.534 & -0.026 & 0.146 \\
\hline ES1 & 0.441 & $\mathbf{0 . 8 6 9}$ & 0.104 & 0.479 & -0.180 & 0.083 \\
\hline ES2 & 0.510 & $\mathbf{0 . 8 7 4}$ & 0.046 & 0.492 & -0.155 & 0.054 \\
\hline ES3 & 0.590 & $\mathbf{0 . 9 0 4}$ & 0.069 & 0.490 & -0.179 & 0.067 \\
\hline ES4 & 0.613 & $\mathbf{0 . 8 9 5}$ & 0.035 & 0.491 & -0.213 & 0.071 \\
\hline F2 & 0.236 & 0.073 & $\mathbf{0 . 7 8 7}$ & 0.287 & 0.430 & 0.420 \\
\hline F3 & 0.212 & 0.007 & $\mathbf{0 . 8 1 0}$ & 0.250 & 0.529 & 0.529 \\
\hline F4 & 0.131 & 0.068 & $\mathbf{0 . 8 5 2}$ & 0.242 & 0.402 & 0.479 \\
\hline F5 & 0.143 & 0.104 & $\mathbf{0 . 8 2 1}$ & 0.216 & 0.456 & 0.481 \\
\hline SP1 & 0.484 & 0.377 & 0.227 & $\mathbf{0 . 8 4 8}$ & 0.085 & 0.173 \\
\hline SP2 & 0.430 & 0.380 & 0.292 & $\mathbf{0 . 8 2 7}$ & 0.141 & 0.123 \\
\hline SP3 & 0.443 & 0.485 & 0.280 & $\mathbf{0 . 8 2 2}$ & 0.024 & 0.121 \\
\hline SP4 & 0.565 & 0.527 & 0.180 & $\mathbf{0 . 7 3 8}$ & -0.050 & 0.017 \\
\hline SP5 & 0.483 & 0.532 & 0.178 & $\mathbf{0 . 7 7 8}$ & -0.078 & 0.119 \\
\hline WQ1 & 0.022 & -0.223 & 0.498 & 0.010 & $\mathbf{0 . 8 8 2}$ & 0.513 \\
\hline WQ2 & 0.036 & -0.193 & 0.488 & 0.022 & $\mathbf{0 . 8 7 7}$ & 0.536 \\
\hline WQ3 & 0.038 & -0.187 & 0.499 & 0.066 & $\mathbf{0 . 8 9 0}$ & 0.478 \\
\hline WQ4 & 0.003 & -0.223 & 0.435 & -0.002 & $\mathbf{0 . 8 9 4}$ & 0.528 \\
\hline WQ5 & 0.111 & -0.115 & 0.459 & 0.124 & $\mathbf{0 . 8 2 5}$ & 0.496 \\
\hline WQ6 & -0.037 & -0.127 & 0.509 & 0.078 & $\mathbf{0 . 8 0 3}$ & 0.531 \\
\hline SCI3 & 0.064 & -0.061 & 0,549 & 0.119 & 0.567 & $\mathbf{0 . 7 2 0}$ \\
\hline SCI4 & 0.292 & 0.293 & 0.334 & 0.235 & 0.279 & $\mathbf{0 . 7 1 3}$ \\
\hline SC15 & 0.296 & 0.105 & 0.397 & 0.193 & 0.420 & $\mathbf{0 . 7 9 7}$ \\
\hline SC16 & 0.037 & -0.025 & 0.447 & -0.012 & 0.476 & $\mathbf{0 . 7 8 5}$ \\
\hline & & & & & & \\
\hline
\end{tabular}


Table 4: Discriminant validity

\begin{tabular}{|l|l|l|l|l|l|l|}
\hline Construct & IS & ES & F & SP & WQ & SCI \\
\hline Informational Support & $\mathbf{0 . 8 8 4}$ & 0.696 & 0.258 & 0.583 & 0.032 & 0.211 \\
\hline Emotional Support & 0.604 & $\mathbf{0 . 8 8 6}$ & 0.075 & 0.550 & -0.207 & 0.079 \\
\hline Flow & 0.219 & 0.090 & $\mathbf{0 . 8 1 8}$ & 0.302 & 0.558 & 0.587 \\
\hline Social Presence & 0.708 & 0.659 & 0.346 & $\mathbf{0 . 7 8 5}$ & 0.057 & 0.224 \\
\hline Web Quality & 0.084 & 0.222 & 0.630 & 0.115 & $\mathbf{0 . 8 6 3}$ & 0.687 \\
\hline Social Commerce Intention & 0.289 & 0.191 & 0.717 & 0.168 & 0.597 & $\mathbf{0 . 7 5 5}$ \\
\hline
\end{tabular}

Note: Square root of the AVE in bold (main diagonal). Fornell-Larcker criterion (above the main diagonal) and the HeterotraitMonotrait Ratio (HTMT) (below the main diagonal)

\subsection{Assessment of the Structural Model}

The recommended method of assessing the structural model is to start by evaluating the square of the coefficient of multiple correlations $\left(R^{2}\right)$, which indicates the amount of variance in the construct due to the model. In our case, $R^{2}$ for the social commerce intention variable is 0.476 and thus far greater than the recommended minimum (0.1) [16].

We then studied the standardised regression coefficients to find the relative importance of the factors in the endogenous variables. Values greater than 0.3 are recommended [8]. However, values greater than 0.2 are permitted in exploratory studies or when they are applied to different sectors. The emotional support - social commerce intention relationship has a lower coefficient than the recommended minimum, and the informational support - social commerce intention and social support - social commerce intention relationships are not significant.

The estimator provided by the Stone-Geisser or $\mathrm{Q}^{2}$ test [19], [53] using blindfolding (Omission Distance $=7$ ), which was used to analyse the predictive capacity of the dependent constructs and the endogenous variables, produced values greater than the recommended minimum (0.4) except for the social presence variable. The greater $Q^{2}$ is, the more predictive relevance a model has. The $Q^{2}$ value for social commerce intention is 0.635 .

The effect size (f2) also verified the suitability of the model. This coefficient measures whether an independent latent variable impacts substantially on a dependent latent variable. $f^{2}$ values of between 0.02 and 0.15 , between 0.15 and 0.35 , and 0.35 or greater indicate whether an exogenous latent variable has small, medium or big effect, respectively [8]. Four of the relationships in table 5 show a small or negligible effect, whilst one has a medium effect.

Lastly, the SRMR (Standardized Root Mean Square Residual) [28] enables us to compare the difference between the observed and predicted correlations and thus adjust the model. A value less than 0.08 is considered acceptable. The value in our model is on the limit, meaning the proposed model adjustment is partially correct.

Table 5: Assessment of the structural model (bootstrapping $=5000)$

\begin{tabular}{|l|l|l|l|l|l|}
\hline Relationship & Path & $\mathrm{f}^{2}$ & $\mathrm{Q}^{2}$ & $\mathrm{R}^{2}$ & SRMR \\
\hline Informational Support $\rightarrow$ Social Commerce Intention & 0.090 & 0.008 & & & \\
\hline Emotional Support $\rightarrow$ Social Commerce Intention & $0.139^{\star *}$ & 0.019 & & & \\
\hline Flow $\rightarrow$ Social Commerce Intention & $0.338^{\star \star *}$ & 0.133 & & & \\
\hline Social Presence $\rightarrow$ Social Commerce Intention & -0.088 & 0.008 & & & \\
\hline Web Quality $\rightarrow$ Social Commerce Intention & $0.439^{\star \star *}$ & 0.228 & & & \\
\hline Informational Support & & & 0.536 & & \\
\hline Emotional Support & & & 0.597 & & \\
\hline Social Presence & & & 0.275 & & \\
\hline Flow & & & 0.435 & & \\
\hline Website Quality & & & 0.410 & & \\
\hline Social Commerce Intention & & & 0.635 & 0.476 & 0.080 \\
\hline
\end{tabular}

Note: ${ }^{* * *} p<0.001,{ }^{* *} p<0.10$.

The results of the analyses confirm and verify the relevance of hypotheses 3 and 5 . Conversely, the analyses provide no empirical support for hypotheses 1 and 4. Based on Chin [8], hypothesis 2 is not supported by sufficient empirical evidence either, since the path coefficient is less than 0.2 despite its significance. However, given the 
exploratory nature of SC research, recent studies have accepted relationships between variables with a path coefficient less than the minimum value cited in the literature as being significant [7], [38].

\section{Discussion}

This section discusses the theoretical and managerial implications of the results. The present study expands the consumer behaviour theory by exploring predictors of intention to social commerce. The findings can help ecommerce practitioners to improve the way they use social tools in their websites.

\subsection{Theoretical Implications}

Social media has changed how we shop online. In addition to the tools which enable businesses to offer their products to consumers, the Internet now has others which allow users to interact with one another by rating and assessing products, thus facilitating purchase decisions. These changes have led to what is known as social commerce (SC), in which users can make and share comments, ratings and reviews of products at any point in the buying process [25], [31], [37]. Previous studies have looked at how different variables influence SC intention on social networking sites [35], [36], [59], [60]. However, there has been little research into factors which influence SC intention on traditional e-commerce sites with integrated social tools (e.g. blogs, reviews, product ratings). To contribute to a better understanding of this field, we have introduced a Social Commerce Intention Model (SCIM) for traditional e-commerce sites where social tools are integrated. The influences of five antecedents to SC intention for traditional e-commerce sites have been assessed. Our model is based on research by [36], [59], and on social support theory, the Stimulus-Organism-Response model and social exchange theory.

The SCIM shows that SC intention on these types of websites is affected mainly by web quality and flow, and to a lesser degree by emotional social support, whilst social presence and informational support have no significant influence. These findings have some important implications for researchers and practitioners interested in social commerce.

First, the positive influence of web quality on SC intention is consistent with previous studies involving social networking sites [10], [36]. The possibility of efficiently sharing experiences and consulting the opinions of other users largely depends on web quality. A good quality website facilitates quick, simple and easy dissemination and access to information, and in fact is the variable in this study with the greatest influence on SC intention. This is why there is a significant difference between our study and other SC studies based on social networking sites, where web quality has a lesser influence than the two social aspects of the website. This suggests a need to look deeper into the role of web quality in different types of SC websites.

Second, flow has a positive influence on SC intention, which is consistent with previous studies [38], [59]. The sensations experienced by the users when they engage in SC awaken their curiosity, interest and imagination, which in turn encourages enjoyment and a retreat from their surroundings. By confirming the influence of flow on traditional e-commerce sites which have integrated social tools, the results of this study therefore broaden the literature and facilitate a better understanding of user intention to participate in SC.

Third, users also have greater SC intentions when they feel emotionally supported by other users, as indicated by previous studies [7], [36], [59]. In our research, however, emotional support has a lesser effect. There are various possible reasons for this. The results may have been influenced by the small size of the SC online community used in our research, or even by the participation of a high number of occasional consumers who do not participate in the community. Furthermore, the nature of the product itself ( $\mathrm{t}$-shirts) may not provide enough of an incentive for user interaction, or may mean that users encounter few difficulties in the buying process requiring the emotional support of other users to help resolve them. This suggests that emotional support has little effect on SC intention in cases involving low-risk, easy-to-purchase, hedonic products. However, we recommend further study into this relationship in order to obtain conclusive results.

Fourth, contrary to what we expected, the effects of social presence and informational social support are not significant. This differs from the findings of [36], [59] in their research into SC which is based on social networks. Social presence may not affect SC intention because of the relative unimportance of the relationships with other consumers. In this case, users may be more interested in obtaining useful advice for improving their purchase decision than interacting with other users to create social links. This could be attributed to the characteristics of the website as well as user profiles. It may be that users feel a certain level of stress when interacting online because of factors such as social comparison or lack of control, amongst others, which could also explain the negative value of the relationship between social presence and SC intention. These results suggest the need for more in-depth study of the influence of social presence on SC websites.

Informational support does not impact on SC intention because users may pay little heed to the information received from other users given the type of product involved (considered low-cost and low-risk). Informational support is typically used for solving problems or confronting difficulties in the purchase process, and we would therefore expect it to affect SC intention. However, this has not been the case. These results suggest that the effect of informational 
support may depend on the nature of the product and the type of purchase, and that it is less significant for hedonic, low-cost purchases. This study therefore broadens the literature on the influence of informational support on SC websites.

Overall, in this type of website SC intention depends on the website functioning properly, a purchase experience which is easy, fast and aesthetically pleasing, and to a lesser extent on the support of other users in choosing and buying their products. Previous studies focussed on social networking sites which mainly seek to establish or maintain relationships or on large e-commerce sites with a high number of users. The website used in our study (Site 1) does not have as many users as other platforms as Amazon (Site 2). It may be that its users essentially want a quality, flawless and aesthetically pleasing experience. They interact with one another, although the social component is not the most important aspect and does not determine the SC intention. This may be because the product is exclusive (it is only marketed on this website and in limited numbers). These characteristics suggest a user profile which values exclusivity and difference. Someone who is part of a minority and therefore not inclined to participate in large communities geared towards the market majority (e.g. Zara). Users are more prone to practice SC when a website fulfils their wishes efficiently and flawlessly, and when the online environment encourages flow.

\subsection{Managerial Implications}

This study contributes to improve the management of traditional e-commerce sites with their own integrated social tools (e.g. forums, reviews). These results can help managers working with these types of websites to decide on the level of social tools they should provide and the extent to which they should be integrated on an e-commerce site, as well as to assess interest in setting up a user community. Such businesses can choose to focus on web and service quality, which may involve eliminating faults in user navigation so that they can navigate quickly and efficiently, and ensuring that the service is delivered under the agreed conditions and within a short time frame. To increase the use of SC, web quality must be improved to promote dissemination and consultation of the information generated by users in an easy, quick and friendly way.

SC intention will also increase if the website encourages a flow experience. Companies must design efficient interactive processes which the user enjoys effortlessly and which encourage the users to lose themselves in the experience. This could be achieved, for example, by designing simple purchase processes where the users can see, select and pay for the products they are interested in with just a few steps. From a social perspective, companies should increase the recommendation options beyond a mere rating, and enable users to express themselves freely through a forum. A flow experience would also be encouraged by allowing users to co-create new products, e.g. suggesting design ideas or commenting on new proposals from the company. Real-time interaction with other users in making their purchase decision would also contribute in this regard.

Social tools are perhaps an important but not determining factor for small e-commerce websites offering low-risk products. They should therefore be incorporated in the website but without becoming the backbone of the business strategy, so that users can receive support if they need it, and participate and interact in ways that inform their purchase decision. However, the use of these tools will depend on the level of user participation, and the company must therefore encourage this. We recommend employing easy-to-use tools which are integrated in the purchase process. Managers need to formulate social commerce strategies, and should demonstrate an active presence across social media platforms to facilitate social interaction with consumers and motivate them to share their experiences regarding products or services.

Another option is to create a community for the most frequent users which encourages, rewards and increases their participation. This may lead to better positioning in search engines, an increase in the amount of information available, cooperation of the community to resolve problems and doubts, and greater SC intention because the user feels more integrated in the group [25], [27], [59].

Lastly, emotional support should also be improved via messages centred around emotional aspects - such as care of others, empathy, understanding, etc. - which make the person receiving the messages feel valued [36] and favour SC intention.

\section{Conclusions}

The SCIM shows that three factors influence consumer behavioural intentions for e-commerce sites with integrated social tools (e.g. chats, forums, product reviews). Their influence in this case is different than in the case of social commerce sites based on social networks. We found that web quality and an immersive experience or flow are more important. Emotional social support is also important, but to a lesser degree than the effect observed for social commerce based on social networks. Websites with integrated tools therefore do not seem to encourage links between users to the same extent. In contract, social presence and informational social support are not significant factors in social commerce intention. The former may be because the relational elements on the website which are used for data collection have little effect, and the latter due to the product being sold. Being a low-risk item, the information obtained from other users is less important. 
Like any empirical study, this research is subject to a series of limitations and should be interpreted with care. The sample was limited to 201 consumers on one e-commerce site with integrated social tools, and its narrow profile may have affected the results. The research could be extended to similar websites involving different products or sectors, and with variations in the size of the user community. Future research could also assess effects between antecedent variables, which would have indirect effects on social commerce intention. We also recommend increasing the dimensions of variables such as flow or web quality to improve knowledge of their effect on social commerce intention. In addition, other relationships between the current variables could be analysed (e.g. social presence and web quality as antecedents of flow). Moreover, the model could be broadened to include other mediating variables such as user trust, satisfaction or their engagement with the community [7], [33], [42], or moderating variables such as age, gender or experience of use, in order to analyse their impact on social commerce intention. Lastly, since this was a transversal study, no assessment was made of how the users themselves developed within the community.

\section{Websites List}

Site 1: Qwertee

https://www.qwertee.com/

Site 2: Amazon

https://www.amazon.com/

\section{References}

[1] I. Ajzen, The theory of planned behaviour, Organizational Behaviour and Human Decision Process, vol. 50, no. 2, pp. 179-211, 1991.

[2] I. Ajzen and M. Fishbein, Understanding Attitudes and Predicting Social Behaviour. New Jersey: Prentice Hall, 1980.

[3] A. Animesh, A. Pinsonneault, S.-B. Yang, and W. Oh, An odyssey into virtual worlds: Exploring the impacts of technological and spatial environments on intention to purchase virtual products, MIS Quarterly, vol. 35, no. 3, pp. 789-810, 2011

[4] D. Barclay, C. Higgins and R. Thompson, The partial least squares (PLS) approach to causal modeling: Personal computer adoption and use as an illustration, Technology Studies, vol. 2, no. 2, pp. 285-309, 1995.

[5] L. S. Beltrán and J. E. E. Blanco, Análisis del estudio de las relaciones causales en el marketing, Revista Innovar Journal, vol. 26, no. 62, pp. 79-94, 2016.

[6] P. Blau, Exchange and Power in Social Life. New York: John Wiley \& Sons, 1964.

[7] J. Chen and X.-L. Shen, Consumers' decisions in social commerce context: An empirical investigation, Decision Support Systems, vol. 79, pp. 55-64, 2015.

[8] W. W. Chin, The partial least squares approach to structural equation modeling, in Modern Methods for Business Research (G. A. Marcoulides, Ed.). Mahwah, NJ: Lawrence Erlbaum Associates Publishers, 1998, pp. 295-336.

[9] J. Choi, H. J. Lee and Y. C. Kim, The influence of social presence on customer intention to reuse online recommender systems: The roles of personalization and product type, International Journal of Electronic Commerce, vol. 16, no. 1, pp. 129-154, 2011.

[10] E. Constantinides and S. J. Fountain, Web 2.0: Conceptual foundations and marketing issues, Journal of Direct, Data and Digital Marketing Practice, vol. 9, no. 3, pp. 231-244, 2008.

[11] J. Crocker and A. Canevello, Creating and undermining social support in communal relationships: The role of compassionate and self-image goals, Journal of Personality and Social Psychology, vol. 95, no. 3, pp. 555-575, 2008.

[12] L. J. Cronbach, Coefficient alpha and the internal structure of tests, Psychometrika, vol. 16, no. 3, pp. 297-334, 1951.

[13] R. Curty and P. Zhang, Social commerce: Looking back and forward, in Proceedings ASIST 2011, New Orleans, LA., 2011, pp. 1-10.

[14] A. Diamantopoulos and H. M. Winklhofer, Index construction with formative indicators: An alternative to scale development, Journal of Marketing Research, vol. 38, no. 2, pp. 269-277, 2001.

[15] A. Diamantopoulos and J. A. Siguaw, Formative versus reflective indicators in organizational measure development: A comparison and empirical illustration, British Journal of Management, vol. 17, no. 4, pp. 263282, 2006.

[16] R. F. Falk and N. B. Miller, A Primer for Soft Modeling. Akron, OH: University of Akron Press, 1992.

[17] C. Fornell and D. F. Larcker, Evaluating structural equation models with unobservable variables and measurement error, Journal of Marketing Research, vol. 18, no. 1, pp. 39-50, 1981.

[18] D. Gefen and D. W. Straub, Consumer trust in B2C e-commerce and the importance of social presence: Experiments in e-products and e-services, Omega, vol. 2, no. 6, pp. 407-424, 2004.

[19] S. Geisser, The predictive sample reuse method with applications, Journal of the American Statistical Association, vol. 70, no. 350, pp. 320-328, 1975. 
[20] B. Gu, J. Park and P. Konana, The impact of external Word-of-mouth sources on retailer sales of highinvolvement products, Information Systems Research, vol. 23, no. 1, pp. 182-196, 2012

[21] Y. Guo and S. Barnes, Why people buy virtual items in virtual worlds with real money, The DATA BASE for Advances in Information Systems, vol. 38, no. 4, pp. 69-76, 2007.

[22] Y. M. Guo and M. S. Poole, Antecedents of flow in online shopping: A test of alternative models, Information Systems Journal, vol. 9, no. 4, pp. 369-390, 2009.

[23] J. F. Hair, G. T. M. Hult, C. Ringle, and M. Sarstedt, A Primer on Partial Least Squares Structural Equation Modeling (PLS-SEM). Thousand Oaks, CA: Sage Publications, 2013.

[24] J. F. Hair, M. Sarstedt, L. Hopkins, and V. G. Kuppelwieser, Partial least squares structural equation modeling (PLS-SEM): An emerging tool in business research, European Business Review, vol. 26, no. 2, pp. 106-121, 2014.

[25] N. Hajli, Social commerce constructs and consumer's intention to buy, International Journal of Information Management, vol. 35, no. 2, pp. 183-191, 2015

[26] A. V. Hausman and J. S. Siekpe, The Effect of Web Interface Features on Consumer Online Purchase Intentions, Journal of Business Research, vol. 2, no. 1, pp. 5-13, 2009.

[27] T. Hennig-Thurau, C. F. Hofacker and B. Bloching, Marketing the Pinball Way: Understanding How Social Media Change the Generation of Value for Consumers and Companies, Journal of Interactive Marketing, vol. 27, no. 4, pp. 237-241, 2013.

[28] J. Henseler, T. K. Dijkstra, M. Sarstedt, C. M. Ringle, A. Diamantopoulos, D. W. Straub and R. J. Calantone, Common beliefs and reality about PLS comments on Rönkkö and Evermann (2013), Organizational Research Methods, vol. 17, no. 2, pp. 182-209, 2014.

[29] J. Henseler, C. M. Ringle and M. Sarstedt, A new criterion for assessing discriminant validity in variance-based structural equation modeling, Journal of the Academy of Marketing Science, vol. 43, no. 1, pp. 115-135, 2015

[30] D. L. Hoffman and T. P. Novak, Marketing in hypermedia computer-mediated environments: Conceptual foundations, Journal of Marketing, vol. 60, no. 3, pp. 50-68, 1996.

[31] Z. Huang and M. Benyoucef, From e-commerce to social commerce: A close look at design features, Electronic Commerce Research and Applications, vol. 12, no. 4, pp. 246-259, 2013.

[32] A. M. Kaplan and M. Haenlein, Users of the world, unite! The challenges and opportunities of social media, Business Horizons, vol. 53, no. 1, pp. 59-68, 2010.

[33] S. Kim and H. Park, Effects of various characteristics of social commerce (s-commerce) on consumers' trust and trust performance, International Journal of Information Management, vol. 33, no. 2, pp. 318-332, 2013.

[34] M. Koufaris, Applying the technology acceptance model and flow theory to online consumer behavior, Information Systems Research, vol. 13, no. 2, pp. 205-223, 2002.

[35] T. P. Liang and E. Turban, Introduction to the special issue social commerce: A research framework for social commerce, International Journal of Electronic Commerce, vol. 16, no. 2, pp. 5-14, 2011.

[36] T. P. Liang, Y.-T. Ho, Y. W. Li, and E. Turban, What drives social commerce: The role of social support and relationship quality, International Journal of Electronic Commerce, vol. 16, no. 2, pp. 69-90, 2011

[37] X. Lin, Y. Li and X. Wang, Social commerce research: Definition, research and the trends, International Journal of Information Management, vol. 37, no. 3, pp. 190-201, 2017.

[38] H. Liu, H. Chu, Q. Huang, and X. Chen, Enhancing the flow experience of consumers in China through interpersonal interaction in social commerce, Computers in Human Behavior, vol. 58, no. 1, pp. 306-314, 2016.

[39] B. Lu., W. Fan and M. Zhou, Social presence, trust, and social commerce purchase intention: An empirical research, Computers in Human Behavior, vol. 56, no. 1, pp. 225-237, 2016.

[40] M. M. A. D. Mamoun and N. A. M. I. Ashouri, Consumer attitudes towards online shopping, Internet Research, vol. 25, no. 5, pp. 707-733, 2015.

[41] P. Mardsen, Social Commerce: Monetizing Social Media. Hamburg. Germany: Syzygy Deutschland Gmbh, 2010.

[42] F. J. Martínez-López, R. Anaya-Sánchez, R. Aguilar-Illescas, and S. Molinillo, Online Brand Communities: Using the Social Web for Branding and Marketing. Heidelberg: Springer International Publishing, 2016.

[43] A. Mehrabian and J. A. Russell, An Approach to Environmental Psychology. Cambridge, MA: The MIT Press, 1974.

[44] C. S.-P. Ng, Intention to purchase on social commerce websites across cultures: A cross-regional study, Information \& Management, vol. 50, no. 8, pp. 609-620, 2013

[45] T. P. Novak, D. L. Hoffman and Y.-F. Yung, Measuring the customer experience in online environments: A structural modeling approach, Marketing Science, vol. 9, no. 1, pp. 22-42, 2000

[46] J. C. Nunnally and I. H. Bernstein, Psychometric Theory. New York: McGraw-Hill, 1994

[47] S. Petter, D. Straub and A. Rai, Specifying formative constructs in information systems research, MIS Quarterly, vol. 31, no. 4, pp. 623-656, 2007.

[48] C. E. Porter and N. Donthu, Cultivating trust and harvesting value in virtual communities, Management Science, vol. 54, no. 1, pp. 113-128, 2008.

[49] L. Quu and I. Benbasat, An investigation into the effects of text-to-speech voice and 3D avatars on the perception of presence and flow of live help in electronic commerce, ACM Transactions on Computer-Human Interaction, vol. 2, no. 4, pp. 329-355, 2005.

[50] C. M. Ringle, S. Wende and J. M. Becker, SmartPLS 3. Bönningstedt: SmartPLS, 2015

[51] E. L. Sallnas, K. Rassmus-Grohn and C. Sjostrom, Supporting presence in collaborative environments by haptic force feedback, ACM Transactions on Computer-Human Interaction, vol. 7, no. 4, pp 461-476, 2000. 
[52] A. T. Stephen and O. Toubia, Deriving value from social commerce networks, Journal of Marketing Research, vol. 47, no. 2, pp. 215-228, 2010.

[53] M. Stone, Cross-validatory choice and assessment of statistical predictions, Journal of the Royal Statistical Society. Series B (Methodological), vol. 36, no. 2, pp. 111-147, 1974.

[54] Q. Tang, B. Gu and A. B. Whinston, Content contribution for revenue sharing and reputation in social media: A dynamic structural model, Journal of Management Information Systems, vol. 9, no. 2, pp. 41-76, 2012.

[55] A. Vaux, Social Support: Theory, Research, and Intervention. New York, NY: Praeger Publishers, 1988.

[56] V. Venkatesh and F. D. Davis, A theoretical extension of the technology acceptance model: Four longitudinal field studies, Management Science, vol. 6, no. 2, pp. 186-204, 2000.

[57] C. Wang and P. Zhang, The evolution of social commerce: The people, management, technology, and information dimensions, Communications of the Association for Information Systems, vol. 31, no. 5, pp. 105127, 2012.

[58] Z. Wang, H. Li., Q. Ye, and R. Law, Saliency effects of online reviews embedded in the description on sales: Moderating role of reputation, Decision Support Systems, vol. 87, no. 1, pp. 50-58, 2016.

[59] H. Zhang, Y. Lu, S. Gupta, and L. Zhao, What motivates customers to participate in social commerce? The impact of technological environments and virtual customer experiences, Information \& Management, vol. 51, no. 8, pp. 1017-1030, 2014.

[60] K. Z. K. Zhang and M. Benyoucef, Consumer behavior in social commerce: A literature review, Decision Support Systems, vol. 86, no. 1, pp. 95-108, 2016

[61] X. Zheng, C. M. K. Cheung, M. K. O. Lee, and L. Liang, Building brand loyalty through user engagement in online brand communities in social networking sites, Information Technology \& People, vol. 28, no. 1, pp. 90106, 2015.

[62] L. Zhou, P. Zhang and H.-D. Zimmermann, Social commerce research: An integrated view, Electronic Commerce Research and Applications, vol. 12, no. 2, pp. 61-68, 2013. 


\section{Appendix A: Measurement Scales}

\begin{tabular}{|c|c|c|}
\hline Construct, code and items & Type of scale & Source \\
\hline $\begin{array}{l}\text { Informational Support } \\
\text { IS1: On the social commerce website, some people would offer } \\
\text { suggestions when I needed help. } \\
\text { IS2: When I encountered a problem, some people on the social commerce } \\
\text { website would give me information to help me overcome the problem. } \\
\text { IS3: When faced with difficulties, some people on the social commerce } \\
\text { website would help me discover the cause and provide me with } \\
\text { suggestions. }\end{array}$ & $\begin{array}{l}\text { 5-point scale from } 1 \\
\text { (strongly disagree) } \\
\text { to } 5 \text { (strongly } \\
\text { agree). }\end{array}$ & [36] \\
\hline $\begin{array}{l}\text { Emotional Support } \\
\text { ES1: When faced with difficulties, some people on the social commerce } \\
\text { website are on my side. } \\
\text { ES2: When faced with difficulties, some people on the social commerce } \\
\text { website comforted and encouraged me. } \\
\text { ES3: When faced with difficulties, some people on the social commerce } \\
\text { website listened to me talk about my private feelings. } \\
\text { ES4: When faced with difficulties, some people on the social commerce } \\
\text { website expressed interest and concern in my well-being. }\end{array}$ & $\begin{array}{l}\text { 5-point scale from } 1 \\
\text { (strongly disagree) } \\
\text { to } 5 \text { (strongly } \\
\text { agree). }\end{array}$ & {$[36]$} \\
\hline $\begin{array}{l}\text { Social Presence } \\
\text { SP1. When surfing the social commerce website, the interaction with the } \\
\text { other customers is personal. } \\
\text { SP2. When surfing the social commerce website, the interaction with the } \\
\text { other customers is warm. } \\
\text { SP3. When surfing the social commerce website, the interaction with the } \\
\text { other customers is close. } \\
\text { SP4. When surfing the social commerce website, the interaction with the } \\
\text { other customers is humanising. } \\
\text { SP5. When surfing the social commerce website, the interaction with the } \\
\text { other customers is emotional. }\end{array}$ & $\begin{array}{l}\text { 5-point scale from } 1 \\
\text { (strongly disagree) } \\
\text { to } 5 \text { (strongly } \\
\text { agree). }\end{array}$ & [59] \\
\hline $\begin{array}{l}\text { Flow } \\
\text { F1. My imagination is aroused when I interact within the social commerce } \\
\text { website. } \\
\text { F2. I feel curious when interacting on the social commerce website. } \\
\text { F3. The interaction on the social commerce website is interesting. } \\
\text { F4. I am absorbed in the interactions on the social commerce website. } \\
\text { F5. It is fun to interact on the social commerce website. }\end{array}$ & $\begin{array}{l}\text { 5-point scale from } 1 \\
\text { (strongly disagree) } \\
\text { to } 5 \text { (strongly } \\
\text { agree). }\end{array}$ & {$[59]$} \\
\hline $\begin{array}{l}\text { Web Quality } \\
\text { WQ1: The social commerce website has a function that allows users to } \\
\text { provide quick responses and feedback. } \\
\text { WQ2: The social commerce website offers me a variety of alternatives for } \\
\text { solving my problems. } \\
\text { WQ3: The social commerce website provides a friendly user interface. } \\
\text { WQ4: The social commerce website makes it easy to contact my friends. } \\
\text { WQ5: The social commerce website makes it easy to provide information to } \\
\text { my friends. } \\
\text { WQ6: The social commerce website has up-to-date hardware and software. }\end{array}$ & $\begin{array}{l}\text { 5-point scale from } 1 \\
\text { (strongly disagree) } \\
\text { to } 5 \text { (strongly } \\
\text { agree). }\end{array}$ & {$[36]$} \\
\hline $\begin{array}{l}\text { Social Commerce Intention } \\
\text { SCI1: I am willing to share my experiences and suggestions when my } \\
\text { friends on the social commerce website want my advice on buying } \\
\text { something. } \\
\text { SCI2: I am willing to share my own shopping experience with my friends on } \\
\text { the social commerce website. } \\
\text { SCI3: I am willing to recommend a product that is worth buying to my } \\
\text { friends on the social commerce website. } \\
\text { SCI4: I will consider the shopping experiences of my friends on the social } \\
\text { commerce website when I want to shop. } \\
\text { SCI5: I will ask my friends on the social commerce website to provide me } \\
\text { with their suggestions before I go shopping. } \\
\text { SCI6: I am willing to buy the products recommended by my friends on the } \\
\text { social commerce website. }\end{array}$ & $\begin{array}{l}\text { 5-point scale from } 1 \\
\text { (strongly disagree) } \\
\text { to } 5 \text { (strongly } \\
\text { agree). }\end{array}$ & {$[36]$} \\
\hline
\end{tabular}

